\title{
Patterns of growth in the hepatic glycogenoses
}

\author{
D B DUNGER, J V LEONARD, AND M A PREECE
}

Departments of Child Health and Growth and Development, Institute of Child Health, London

SUMMARY Longitudinal growth data from 31 patients with hepatic glycogen storage disease (type I (8 patients), type Ib (three patients), type III (13 patients), and type IX (phosphorylase kinase deficiency) ( 7 patients)) have been reviewed. All patients were below the mean for height at presentation; the mean height standard deviation scores were $-2 \cdot 13$ (type I), $-2 \cdot 0$ (type Ib), $-2 \cdot 4$ (type III), and -1.6 (type IX). Untreated, most patients with type I and Ib grew slowly with no catch up growth but three patients with mild disease grew normally. Most children with type III disease grew at a normal velocity throughout childhood. Puberty was delayed and final height normal. Some of the children with type III and all of those with type IX had catch up growth throughout childhood. Intensive treatment of patients with severe forms of type I and Ib disease resulted in catch up growth, but this was not complete if the treatment was started late.

Growth delay may occur in all of the common types of hepatic glycogen storage disease ${ }^{1}$ (glucose-6-phosphatase deficiency, type I and type $\mathrm{Ib} ;^{2}$ debrancher deficiency, type III; and phosphorylase kinase deficiency, type IX). ${ }^{3}$ Fine $e t$ al, ${ }^{4}$ in a long term follow up study of four children with type I disease noted severe growth retardation with delayed sexual maturation.

With intensive treatment the growth rate of growth retarded children with type I hepatic glycogen storage disease may increase strikingly. 56 Children with type III and IX disease may also have delayed sexual maturation but growth retardation is less pronounced.' As longitudinal growth data are limited, we studied the growth of 31 children with these disorders.

\section{Patients and methods}

Between 1952 and 1980 a diagnosis of hepatic glycogen storage disease was made in 40 children admitted to the Hospital for Sick Children, London. Longitudinal growth data suitable for analysis were available in 31 of these patients. Eight had type I, 13 had type III, and 7 had type IX disease. The diagnosis was confirmed at liver biopsy in all the patients with type I, 6 of those with type III, and 6 of the children with type IX disease. The remainder were diagnosed by assay of the appropriate enzyme activities in red and white blood cells. Enzyme activities were determined in the laboratories of Professor A D Patrick (Institute of Child Health,
London) using standard methods. ${ }^{7-9}$ Three other patients had the clinical features of type I hepatic glycogen storage disease with failure of glycaemic response to both glucagon and galactose, lactic acidaemia, increased hepatic glycogen, but normal activities of glucose-6-phosphatase and fructose 1-6 diphosphatase in liver that had been frozen. These have been classified as type $\mathrm{Ib} .^{2}$ Two of these patients had neutropenia and a neutrophil mobility defect. ${ }^{11}$

Longitudinal growth data were available from the records of attendance in the outpatients department and where the patients had been referred back to the local medical services the relevant paediatrician was asked for details of the patient's growth. These height data were compared with the normal data of Tanner, Whitehouse, and Takaishi ${ }^{11}$ and height SD scores were calculated as described by those authors. Bone age maturity scores were calculated by the TW2-RUS method.'

During the study 6 of the children with type I and Ib disease were started on treatment with regular drinks of a glucose polymer (Caloreen, Roussel) by day and nasogastric tube feeds of the glucose polymer at night $;^{6}$ they received approximately 0.5 $\mathrm{g} / \mathrm{kg} /$ hour of glucose throughout the 24 hours (patients A1, A3, A4, A6, B1, and B2). Lactose and sucrose in their diet was restricted. All the children with type IX disease were untreated. Five of those with type III were encouraged to take a high protein diet (patients $\mathrm{C} 1, \mathrm{C} 2, \mathrm{C} 3, \mathrm{C} 11$, and C12) with a milk drink at night, but this treatment was not followed consistently. 


\section{Results}

Height at diagnosis. At the time of diagnosis all of the patients were below the mean for height and some were very short. The mean height SD scores of children with different types of hepatic glycogen storage disease were; type I (mean (SD)) -2.13 $(1 \cdot 45)$, type Ib $-2 \cdot 0(1 \cdot 27)$, type III $-2 \cdot 4(1 \cdot 18)$, and type IX $-1.6(1 \cdot 27)$. Where the bone age data were available (14 patients) maturity was found to be delayed by approximately the same extent as height. The mean bone age SD scores were: type I -2.5 (4 patients), type Ib $-1.5(2)$, type III -1.3 (5), and type IX $-1 \cdot 3(5)$.

Longitudinal growth data. Longitudinal growth data presented as height SD scores in these four types of hepatic glycogen storage disease are shown in Figs. 1 to 4 . Untreated, most children with type I and Ib grew slowly, tending to fall further below the mean, with no evidence of catch up growth (Figs. 1 and 2). The oldest child (A1) showed no signs of puberty or catch up growth at the age of 15 years-his bone age being 11 years, height SD score $-6 \cdot 0$, and height velocity SD score $-2 \cdot 8$. There were, however, three exceptions-two girls and one boy with type I disease (A5, A7, and A8) grew normally without any treatment and without any bone age delay. All of the children with type I and Ib disease who were

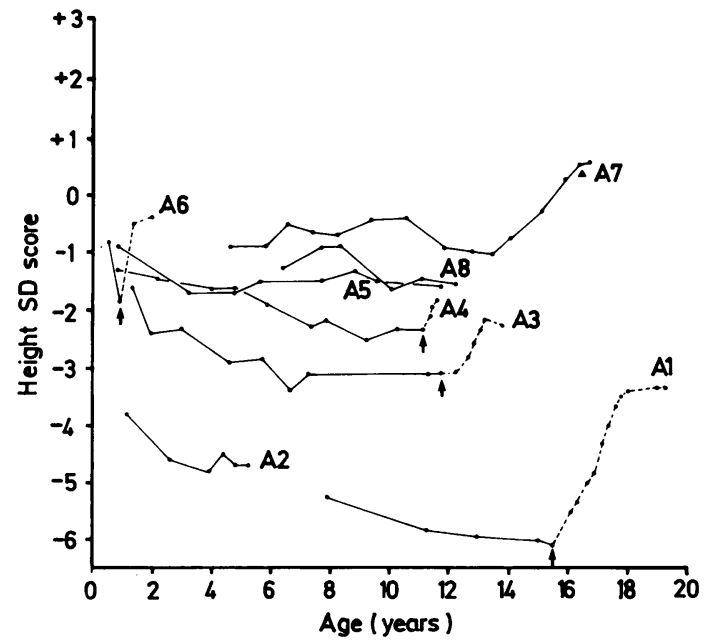

Fig. 1 Longitudinal height data, presented as height standard deviation scores, of patients with hepatic glycogen storage disease, type I. The arrow indicates start of treatment (see text) and the interrupted line the growth thereafter. Onset of menstruation in girls shown by solid triangle ( $\mathbf{\Delta})$.

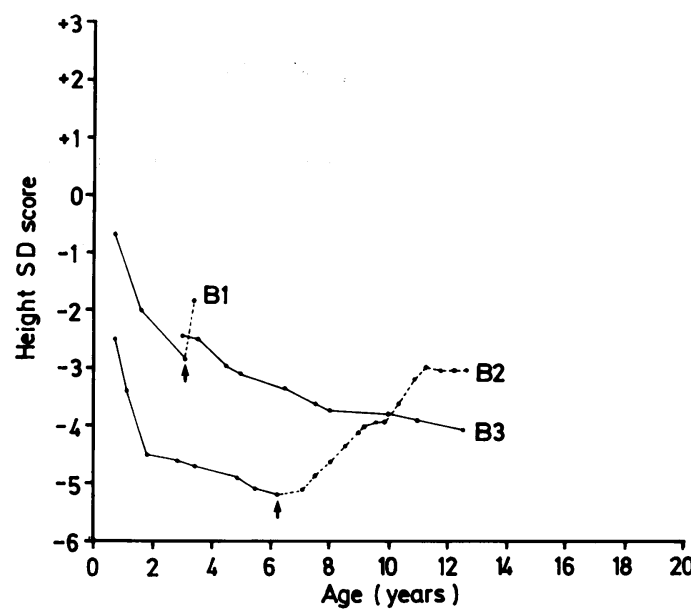

Fig. 2 Longitudinal height data, presented as height standard deviation scores, of patients with hepatic glycogen storage disease, type $\mathrm{Ib}$. The arrow indicates start of treatment (see text) and the interrupted line the growth thereafter.

started on regular glucose drinks by day and nasogastric tube feeds of glucose at night showed accelerated growth (A1, A3, A4, A6, B1, and B2). Four of the children, after an initial period of catch up growth, continued with a normal velocity. Bone age showed corresponding catch up growth but did not accelerate beyond the chronological age. All

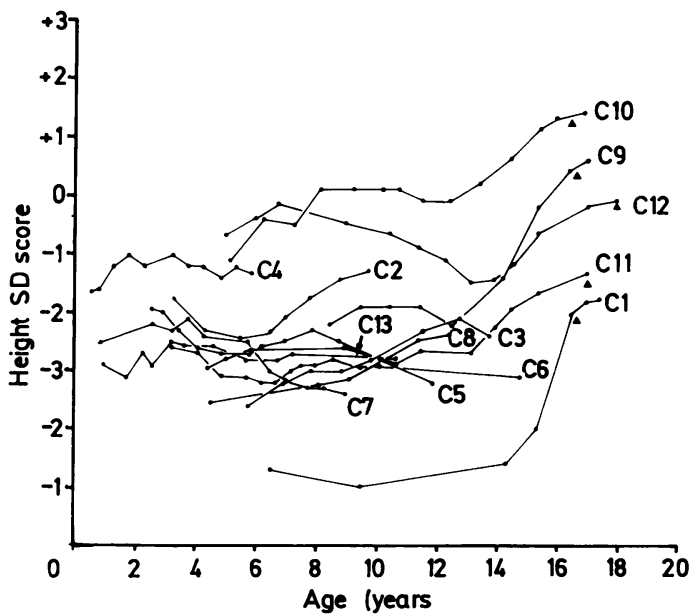

Fig. 3 Longitudinal height data, presented as height standard deviation scores, of patients with hepatic glycogen storage disease, type III. Onset of menstruation in girls shown by solid triangle $(\mathbf{\Delta})$. 


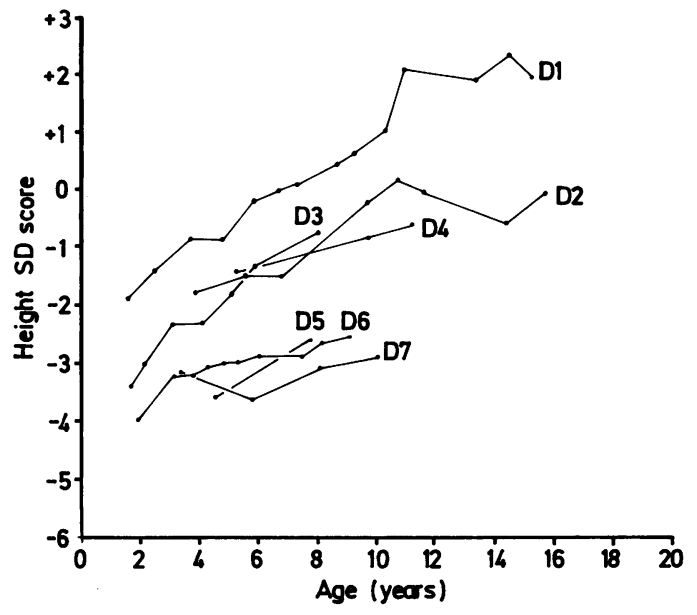

Fig. 4 Longitudinal height data, presented as height standard deviation scores, of patients with hepatic glycogen storage disease, type IX.

children were prepubertal, with the exception of patient A1 who was started on treatment at age $151 / 2$ years (bone age 11 years) and started puberty at the age of $161 / 2$ years: His final height was $154 \mathrm{~cm}$ (limits predicted from parental heights 161 to $178 \mathrm{~cm}$ ). At the age of 19 years, when growth had ceased, his bone age remained immature at 14 years. One patient (B3) with type Ib disease was treated elsewhere by portal diversion ${ }^{13}$ at the age of 6 years. Growth velocity was unchanged after surgery.

Children with type III hepatic glycogen storage disease also tended to be short at diagnosis but the subsequent pattern of growth differed from children with type I disease (Fig. 3). In many of the children there was catch up growth during childhood or at the time of puberty.

Five of the children have passed through puberty. Final heights in all were within 2 SD of the adult mean and where parental height data were available, heights were well within target limits. ${ }^{14}$ The onset of puberty was delayed in these children (onset 14 to 16 years; menarche $161 / 2$ to 18 years). A typical example is patient $\mathrm{C} 9$ who received no treatment. At the age of 8.5 years her height was 2.5 SD below the mean and her skeletal age was 5 years. Puberty began around 15 years of age (skeletal maturation 13.5 years) and she had a normal growth spurt; her final height was +0.6 SD and menarche occurred at $16^{1 / 2}$ years.

Children with type IX disease tended to show gradual catch up growth throughout childhood (Fig. 4). The heights of two brothers (D1 and D2) were -0.9 and -1.7 SD respectively at diagnosis.
Gradual catch up growth occurred and by the age of 11 years their heights were $+2 \cdot 1$ and $+0 \cdot 3$ respectively. Puberty was not delayed and final heights were within parental height targets.

\section{Discussion}

We present longitudinal growth data from 31 patients with hepatic glycogen storage disease. The data are not perfect as they were obtained retrospectively from charts and are likely to be subject to observational errors; but despite this limitation, because of the long period and number of patients studied, clear growth patterns emerge. Untreated, most of the patients with type I and Ib disease grew slowly with no catch up growth. There were three exceptions (all with type I disease) who had a mild disease without documented hypoglycaemia and grew normally. The untreated children with type III disease showed growth and pubertal delay but their final heights were normal. Some of the children with type III and all of those with type IX disease showed catch up growth throughout childhood.

Intensive treatment of children with type I and Ib disease resulted in catch up growth and the prognosis for growth was excellent if treatment was started early. Treatment also reverses the endocrine abnormalities $^{15}$ and may affect favourably the formation of adenomata, ${ }^{16}$ but it is not without dangers as sensitivity to hypoglycaemia is restored. ${ }^{17}$ As some children with type I disease will grow normally without treatment it is clearly not indicated for all patients.

The mechanisms governing growth delay in these children are not clear. We have recently shown that the severity of growth delay can be correlated with endocrine change (principally low concentrations of insulin and somatomedin with raised plasma cortisol) ${ }^{15}$ and suggested that these changes are part of an overall adaptation to decreased hepatic glucose production. Those children with mild disease tend to have a normal glucose response during the fasting glucagon test ${ }^{18}$ and may be more able to maintain glucose output from the liver. In patients with type III and IX disease glucose release from gluconeogenesis may be sufficient to allow for catch up growth during childhood as the requirement for glucose, expressed per $\mathrm{kg}$ body weight, declines after the age of 6 years. ${ }^{19}$

We thank all the paediatricians who kindly referred patients and supplied data for analysis and $\mathrm{Dr} \mathrm{N}$ Cameron for estimating skeletal maturity.

\section{References}

' Cornblath M. Schwartz R. Disorders of carbohydrate metab- 
olism in infancy, In: Shaffer AJ. Markowitz M. ed. Major problems in clinical pediatrics. vol 3. Philadelphia. London and Toronto: W B Saunders, 1976:231-93.

2 Senior B. Loridan L. Studies of liver glycogenosis with particular reference to the metabolism of intravenously administered glycerol. N Engl J Med 1968:279:958-65.

${ }^{3}$ Hug G. Pre and post natal diagnosis of glycogen storage disease. In: Burman D, Holton JB, Pennock CA, eds: Inherited disorders of carbohydrate metabolism. Lancaster: M T P Press, 1980:327-67.

+ Fine RN, Frasier SD, Donnell GN. Growth in glycogen storage discase Type I. Am J Dis Child 1969:117:169-77.

5 Crigler JR, Jr, Folkman J. Glycogen storage discase: new approaches to therapy. In: Porter R. Whelan J, eds. Hepatotrophic factors. Amsterdam: Ciba Foundation Symposium, 1978:331-51.

- Fernandes J. Jansen H. Jansen TD. Nocturnal gastric fecding in glucose-6-phosphatase deficient children. Pediatr Res 1979:13:225-9.

${ }^{7}$ Steinitz K. Laboratory diagnosis of glycogen storage diseases. Adv Clin Chem 1967:9:227-354.

* Spencer Peet J. Norman ME, Lake BD. McNamara J. Patrick AD. Hepatic glycogen storage discase: clinical and laboratory findings in 23 cases. $Q J$ Med 1971:40:95-114.

"Lederer B. Van Hoof E. Van den Berghe G, Hers HG. Glycogen phosphorylase and its converter enzymes in hacmolysates of normal human subjects and patients with Type VI glycogen storage disease. Biochem J 1975;147:23-35.

1" Beaudet AL. Anderson DC. Michels VV. Arion WJ, Lange AJ. Neutropenia and impaired neutrophil migration in Type Ib glycogen storage diseasc. J Pediatr 1980:97:906-10.

"Tanner JM. Whitchouse RH. Takaishi M. Standards from birth to maturity for height. weight, height velocity and weight velocity: British children. 1965. Parts I and II. Arch Dis Child 1966:41:454-71, 613-35.

12 Tanner JM. Whitchouse RH. Marshall WA. Healy MJR. Goldstcin H. Assessment of skeletal maturity and prediction of adult height (TW2 method). London: Academic Press. 1975.

13 Starzl TE, Putnam GW. Porter KA. et al. Portal diversion for the treatment of glycogen storage disease in humans. Ann Surg 1973:178:525-39.

it Tanner JM, Goldstein H. Whitehouse RH. Standards for children's height at ages 2 to 9 years. allowing for height of parents. Arch Dis Child 1970;45:755-62.

15 Dunger DB. Holder AT. Leonard JV. Okac J. Preece MA. Growth and endocrine changes in hepatic glycogenoses. Eur $J$ Pediatr 1982:138:226-30.

16 Roe TF. Kogut MD. Buckingham BA. Miller JH. Gates GF. Landing $\mathrm{BH}$. Hepatic tumours in glycogen storage disease Type I. Pediatr Res 1979:13:931-6.

17 Leonard JV. Dunger DB. Hypoglycaemia complicating feeding regimens for glycogen storage disease. Lancet 1978;ii: 1203-4.

18 Dunger DB. Clinical and metabolic studies of hepatic glycogen storage disease. London: University of London, 1982. (Thesis).

19 Beer DM, Leake RD. Haymond MW, et al. Measurement of 'true' glucose production rates in infants and childhood with 6.6 didenteroglucose. Diabetes 1977;26:1016-23.

Correspondence to Dr D B Dunger, Department of Child Health, Institute of Child Health, 30) Guildford Street. London, WCIN $1 \mathrm{EH}$.

Received 30 March 1984 